\title{
Miguel Torga e a natureza do sentimento: Uma leitura da paisagem em "A Maria Lionça”
}

\author{
Márcia Manir Miguel Feitosa \\ (Universidade Federal do Maranbão)
}

\section{RESUMO}

Leitura do conto "A Maria Lionça", do português Miguel Torga, sob o viés do espaço simbólico e imaginário construído enquanto representação da memória do povo transmontano, mergulhado em seus costumes, crenças e tradições.

PALAVRAS-CHAVE: paisagem; memória; humanismo.

\section{ABSTRACT}

This paper is a reading of the short story "A Maria Lionça", written by the Portuguese writer Miguel Torga under the light of the symbolic and imaginary space built as representation of the people from behind the montauins who are deep in their costumes, beliefs and traditions.

KEYWORDS: landscape; memory; humanism. 
"Nas cidades a vida é mais pequena

Que aqui na minha casa no cimo deste outeiro.

$\mathrm{Na}$ cidade as grandes casas fecham a vista à chave,

Escondem o horizonte, empurram o nosso olhar para longe de todo o céu, Tornam-nos pequenos porque nos tiram o que os nossos olhos não podem dar, E tornam-nos pobres porque a nossa única riqueza é ver."

(Alberto Caeiro)

\section{Introdução}

Miguel Torga é um escritor humanista. Nutre um amor entranhado pelo homem. Mas, para além desse caráter, há o homem transmontano, imerso na realidade agreste de sua região natal com a qual compôs a maioria de seus contos, escritos como sonhos vividos, acalentados no silêncio da montanha. Marcadamente regionalista, a linguagem de Torga é solidária à miséria e à rusticidade que distanciam o homem da montanha do homem da planície, incitando o leitor a sentir em tal espontaneidade a grandeza de espírito de seus personagens. Ao adotar essa voz coletiva que comanda suas narrativas, Torga estreita a distância entre o narrador e o fato narrado, identificando-se com a paisagem rude das montanhas que também endurece o coração de homens e mulheres.

Em nome desse amor incondicional à Humanidade, escreveu uma prosa de ficção à altura dos grandes prosadores portugueses e, notadamente, em Contos de montanha (1941), alçou degraus de exaltação da terra primitiva e de seus habitantes, num misto de limpidez e de consciência do sentido trágico da vida.

"A Maria Lionça", conto que abre o livro, reflete esse estado de coisas. Nele é possível constatar a força telúrica que move as ações de quem vive na montanha integrado ao cosmo, de tal modo que o caráter e a conduta passam a ser moldados pela pureza que caracteriza o mundo transmontano. A personagemtítulo constitui a "legenda de Galafura", espaço geográfico que serve de cenário para os acontecimentos, ao mesmo tempo em que se reveste de uma significação profundamente simbólica.

Ao lado dessa configuração do espaço geográfico, o presente estudo se propõe a empreender uma leitura da representação do imaginário construído no discurso da memória, impregnado de um olhar especial sobre a paisagem estética e marcadamente simbólica. À luz de reflexões em torno da geografia cultural, com destaque para Paul Claval e Yi-Fu Tuan, objetiva-se aproximar o universo da análise literária das ideias associadas à topofilia, em que se evidencia a inter-relação entre sentimento e lugar, ou entre a natureza do sentimento e o "arquivo de lembranças afetivas" que o lugar inspira.

\section{A Terra de Galafura: "O universal sem paredes"}

A Freguesia de Galafura, local onde se desenrolam os acontecimentos mais significativos de conto de Torga, situa-se à margem direita do rio Douro, em Portugal, a uma altitude de cerca de 535 metros. O lendário "Monte de S. Leonardo de Galafura", cantado e imortalizado por Torga, é um miradouro situado a este da povoação, de onde é possível avistar paisagens deslumbrantes. Acredita-se que os romanos foram os responsáveis pela fundação de Galafura, no lugar hoje denominado "Fonte dos mouros", onde se localiza uma necrópole 
medieval conhecida como "Cemitério dos mouros". Talvez possa advir daí a motivação toponímica que deu nome à freguesia. Assim, "Galafura" reporta-se ao nome de um rei mouro que governou o fortim de S. Leonardo, denominado "Galafre".

A frase que abre o conto: "Galafura, vista da terra chã, parece o talefe do mundo.” (Torga, 1996, p. 15) já desvela a grandiosidade que o narrador vai procurar imprimir a essa terra no decorrer de sua narração. Adota a perspectiva, muitas vezes hiperbólica, de quem a admira como o marco geodésico do mundo, ainda que "encardido pelo tempo". Paul Claval destaca, em Geografia cultural, que nomear os lugares é impregná-los de cultura e poder: "O batismo do espaço e de todos os pontos importantes não é feito somente para ajudar uns e outros a se referenciar. Trata-se de uma verdadeira tomada de posse (simbólica ou real) do espaço." (Claval, 2001, p. 189).

Esse narrador que enfatiza o caráter simbólico de Galafura desbrava, ainda, para o leitor os caminhos que levam até Maria Lionça, a senhora da "montanha". Semelhante referência é apontada numa única frase, logo encadeada com Maria Lionça, como a compor uma igualdade: montanha = Maria Lionça. $\mathrm{O}$ trecho a seguir elucida claramente essa relação biunívoca: "Lá, é uma rua comprida, de casas com craveiros à janela, duas quelhas menos alegres, o largo, o cruzeiro, a igreja e uma fonte a jorrar água muito fria. Montanha. $\mathrm{O}$ berço digno da Maria Lionça." (Torga, 1996, p. 15).

Desse parágrafo em diante, o foco passa a ser a personagem, com o desvio da câmara que sinaliza para o tempo, em cujo passado o presente se justifica. O estudioso Augusto Fernandes sustenta que:

(...) a narração de sua vida é agora introduzida pelo episódio da sua morte, querendo significar que a morte tem um efeito epifânico, um poder iluminante sobre o que ficou para trás e se chamou vida. Ou seja, é à luz da morte que se deve ler a legenda aludida no incipit e cuja essência é constituída pelos acontecimentos de que se tecera a vida de Maria Lionça. (apud Weber e Thimóteo, 2008, p. 03)

Assim, à luz da morte, sob a incredulidade de todos, até mesmo do prior, Galafura perdeu a sua legenda. O anúncio dado pelo médico da iminente fatalidade instaura entre seus habitantes o vazio, a escuridão. Afinal, morrera, de forma absurda, o "sol de Galafura", à semelhança da fonte da Corredoura, "que era eterna, por ser um olho marinho".

A seiva que nutria o solo de Galafura havia expirado, porém restava o relato enlevado de sua trajetória altiva e sublime que, sem dúvida, imortalizaria a personagem/mito. Enfim, nas páginas que se seguem à morte de Maria Lionça, o que se descortina é a vida da mulher montanhosa que se torna esposa e mãe. Penélope e Pietà. Esperançosa e sofredora.

\section{A Via Sacra e sua unidade telúrica}

Obedecendo à linearidade dos fatos, o narrador, embevecido, traça o perfil incólume de Maria Lionça, desde a mais tenra idade até a velhice quando abandona o coração de seus conterrâneos. Imune às doenças e respeitada pelos jovens, era quase inalcançável, "como a um fruto dum ramo cimeiro que a natureza quisesse amadurecer plenamente, sem pedrado, num sítio alto onde só 
um desejo arrojado e limpo o fosse colher." (TORGA, 1996, p. 17). Concebida assim, Maria Lionça equipara-se à montanha donde se origina: admirada como um fruto proibido e altaneiro. Simboliza o que Jean Chevalier e Alain Gheerbrant afirmam quando o assunto é "montanha":

vista do alto, ela surge como a ponta de uma vertical, é o centro do mundo; vista de baixo, do horizonte, surge como a linha de uma vertical, o eixo do mundo, mas também a escada, a inclinação a se escalar. (...) A montanha exprime ainda as noções de estabilidade, de imutabilidade, às vezes, até mesmo de pureza. (1995, p. 616)

Enquanto eixo de Galafura, havia, em seu entorno, uma aura de pureza para a qual convergiam todas as virtudes da povoação. Logo, quem escalaria um lugar ao seu lado? Curiosamente, o escolhido fora o ex-militar Lourenço Ruivo, o que, etimologicamente, nasceu em Laurento, adornado com louros, caracterizado pela vaidade e pela fama. Curiosamente ainda é o que não se verifica: é fraco e age como desertor, abandonando mulher e filho, e só retorna, qual "ovelha desgarrada", laureado de vícios e de desengano. Imutável e estável como a montanha, Maria Lionça se manteve à frente das atribulações, serena como o ar de Galafura.

Yi-Fu Tuan, no inspirado livro Espaço e lugar: a perspectiva da experiência (1983), reflete acerca de tal perspectiva de um modo que parece corresponder ipsis litteris ao ideal defendido por Torga, ao assinalar que "a cidade ou terra é vista como mãe e nutriz; (...) o lugar é permanente e por isso tranqüiliza o homem, que vê fraqueza em si mesmo e chance e movimento em toda parte." (Tuan, 1983, p. 171). Tendo degredado para "o outro lado do mar", Lourenço Ruivo migra para o espaço, onde reina a liberdade, a amplidão e a ameaça, mas, necessitado do amparo, do aconchego e de um porto seguro diante da morte, refugia-se no colo de sua mulher que representa mais uma vez a própria Galafura. Assim, as ideias de espaço e lugar nesse conto de Torga adquirem plena significação, à medida que configuram princípios que, no tocante à experiência, se fundem, mas que se diferenciam na medida mesma da dotação de valor.

O lugar é uma classe especial de objeto. É uma concreção de valor, embora não seja uma coisa valiosa, que possa ser facilmente manipulada ou levada de um lado para o outro; é um objeto no qual se pode morar. O espaço, como já mencionamos, é dado pela capacidade de mover-se. Os movimentos freqüentemente são dirigidos para, ou repelidos por, objetos e lugares. Por isso o espaço pode ser experienciado de várias maneiras: como a localização relativa de objetos ou lugares, como as distâncias e extensões que separam ou ligam os lugares, e - mais abstratamente - como a área definida por uma rede de lugares. (Tuan, 1983, p. 14)

Para o espaço ameaçador e símbolo de liberdade foge também o filho Pedro, desencantado com o Lourenço sem fama e vaidade. Torna-se marinheiro, "movediço como a insensatez da sua idade". Rompe, tal como o pai, com o que dele se esperava. Uma vez da pedra, da natureza mineral da pedra, deveria fincar raízes em terra, e não perder-se no mar. O narrador destaca essa contraposição ao compará-lo com o pai: 
E Galafura, humosa, enraizada no dorso da serra de S. Gunhedo, olhava esse rebento, mergulhado em água, como um proscrito. Antes o degredo do pai no Brasil, ao menos aproado a um chão que fazia parte da cosmogonia de Galafura. Diluída na imensidão do mar, a imagem do rapaz perdera toda a nitidez. (Torga, 1996, p. 22)

Vivendo, pois, numa situação de ambivalência em que não é mais possível avistar a terra firme, Pedro é engolido pela morte. De forma curiosa, o único meio de comunicação entre o degredo e Galafura se dá pelos correios e, mais curiosamente ainda, é a notícia da morte ou algo próximo dela que Maria Lionça recebe todas as vezes em que aguarda o retorno ou do marido, ou do filho. Durante quinze anos, qual Penélope à espera do amado Ulisses, alimentou, "firme e corajosa", o regresso de Lourenço. Mais alguns anos foram necessários para que pudesse resgatar do mar bravio e traidor o filho Pedro. Um telegrama foi o suficiente para que trouxesse nos braços o filho morto, à imagem de Maria, mãe de Cristo, a Pietà.

O gênero textual carta/telegrama exerce função interessante no conto, haja vista que se presta à função de fornecer "notícias familiares". Maria Auxiliadora Bezerra, ao estudar o gênero carta, destaca o pensamento de Vera L. Paredes Silva (1997), autora do texto "Variações tipológicas no gênero textual", para quem há variados tipos de cartas, ora funcionando como pedidos, ora como agradecimentos, informações, cobrança, intimação, notícias familiares, prestação de contas, propagandas etc. Ainda que cartas, são de natureza diversa, uma vez que circulam em campos diferentes de atividade. Constituem, devido às suas funções comunicativas variadas, subgêneros do gênero maior "carta", dado que possuem a estrutura básica em comum: a seção de contato, o núcleo da carta e a seção de despedida. O que, de fato, os diferencia são as intenções do autor. Daí a existência de formas variadas de realização, como a carta pedido, a carta resposta, a carta pessoal, a carta programa, a carta circular, a carta do e ao leitor e outras.

No que concerne especificamente ao seu uso em "A Maria Lionça", ao leitor não é dado conhecer o teor, por exemplo, do telegrama que a personagem recebera da capitania de Leixões, mas é possível subentender o porquê de sua atitude de deixar pela primeira vez Galafura e enfrentar o mar e a cidade ameaçadora. Sempre em razão dos que vivem a ou na montanha é que se manifesta a mudança de comportamento. A notícia funcionou, assim, como o motor que impulsionou Maria Lionça para o resgate do filho das águas que afogam a coragem e a determinação e que tanto mal provocaram aos que se dedicam à terra.

Quanto à carta que ansiosamente espera ao longo de quinze anos, desde a partida/deserção do marido, a que finalmente recebe está imersa na mais profunda obscuridade. O marido apenas noticiara que estava regressando, qual o filho pródigo que retorna ao lar. Da constatação de sua real condição até o abandono do filho e a morte deste foi um passo, ou melhor, um simples telegrama. Enfim, a carta e o telegrama, ao mesmo tempo em que descortinam a dura realidade que Galafura ou Maria Lionça tem que enfrentar, reafirmam o retorno dos desgarrados à montanha de onde nunca deveriam ter saído. $\mathrm{O}$ elo que interliga o mundo de fora, representado pela planície ou pelo mar, ao mundo de dentro, representado por Galafura ou pela montanha, é justamente a carta, a notícia que chega e encurta as decisões de Maria Lionça. O arauto de Maria Lionça é a sua consciência lúcida e 
decidida que anuncia a necessidade de abrigar em seu colo o marido e o filho que se degredaram.

Gaston Bachelard, em A poética do espaço, ao tratar do espaço casa ("nosso canto do mundo"), aproxima, metaforicamente, a ideia concebida por Torga ao criar Maria Lionça e sua metonímia: Galafura. Para o fenomenólogo, "a casa é uma das maiores (forças) de integração para os pensamentos, as lembranças e os sonhos do homem." (Bachelard, 2008, p. 26). E continua:

$\mathrm{Na}$ vida do homem, a casa afasta contingências, multiplica seus conselhos de continuidade. Sem ela, o homem seria um ser disperso. Ela mantém o homem através das tempestades do céu e das tempestades da vida. É corpo e é alma. É o primeiro mundo do ser humano. Antes de ser "jogado no mundo", como o professam as metafísicas apressadas, o homem é colocado no berço da casa. E sempre, nos nossos devaneios, ela é um grande berço. Uma metafísica concreta não pode deixar de lado esse fato, esse simples fato, na medida em que ele é um valor, um grande valor ao qual voltamos nos nossos devaneios. O ser é imediatamente um valor. A vida começa bem, começa fechada, protegida, agasalhada no regaço da casa. (Bachelard, 2008, p.26).

Lourenço Ruivo e Pedro retornam do mundo disperso em que apenas figuravam com pouca nitidez para o "regaço eterno de Maria Lionça", onde a vida de fato tem valor. Bachelard ressalta a importância desse "primeiro mundo do ser humano", em que reina a continuidade e a proteção, no entanto Torga defende que esse berço do homem se estenda para sempre, contra todos os atrativos do mundo exterior que deslocam o ser da sua alma verdadeira. A montanha, para Torga, assume essa condição: está inscrita fisicamente no coração do homem transmontano.

Yi-Fu Tuan, no capítulo "Cultura, experiência e atitudes ambientais", do livro Topofilia: um estudo da percepção, atitudes e valores do meio ambiente (1980), registra, no tocante à montanha enquanto "elemento permanente no mundo do homem", que, ao longo da história humana, as atitudes em relação a ela têm mudado e assumido conotações dignas de reflexão. Nas primícias da história, destaca o autor:

a montanha foi vista com assombro. Ela elevava-se acima das planícies habitadas; era remota, difícil de se aproximar, perigosa e inassimilável às necessidades do trabalho diário do homem. Povos em diferentes partes do mundo consideravam a montanha como o lugar onde o céu e a terra se encontravam. Era o ponto central, o eixo do mundo, o lugar impregnado de poder sagrado, onde o espírito humano podia passar de um nível cósmico para o outro. (Tuan, 1980, p. 81).

Assim, Tuan, com o intuito de colher "respostas estéticas" a respeito da montanha, concluiu que estas variavam de cultura para cultura, de povo para povo. Os primeiros gregos, por exemplo, diante de um elemento da natureza o qual não podiam apreender em sua totalidade, sentiam pela montanha tanto o receio, o 
temor, quanto a aversão, a ojeriza. Para Ésquilo, os altos rochedos, ao mesmo tempo em que penetravam o céu, pareciam selvagens e aterrorizantes. Tanto no Ocidente quanto no Oriente a mudança de atitude em relação à montanha não se comportou de modo idêntico, mas, em linhas gerais, como salienta Tuan:

pode ser discernida uma seqüência comum: em ambas as civilizações houve uma mudança da atitude religiosa - na qual o temor se combina com a aversão - para uma atitude estética que se transformou, de um sentimento pelo sublime, para um sentimento pelo pitoresco; para a avaliação moderna das montanhas como recurso recreativo. (Tuan, 1980, p. 82)

Até o advento do Romantismo na Europa, o sentimento que a montanha despertava era ainda de aversão. Tuan ressalta que poucos eram os adjetivos neutros; em grande parte expressavam desprazer, como rude, arrogante, árida, deserta, rústica, solitária, melancólica, insolente ou, ainda, eram descritas como abscessos, verrugas, tetas da Terra, tumores, vesículas.

Já com o Romantismo, o que se evidencia é o canto de louvor à montanha que levava os homens ao êxtase. A mudança de atitude se deve, segundo Nicolson, citado por Tuan, ao abandono da ideia de que o círculo representava a perfeição. O planeta Terra não consistia numa esfera perfeita, dada sua forma irregular, composta por montanhas disformes e profundidades oceânicas, resultado da queda do paraíso. À medida que as comprovações científicas revelaram a contradição desse pensamento e o padrão de beleza começou a se pautar não mais em simples formas geométricas, novas tendências intelectuais trilharam um novo caminho para a apreciação das montanhas.

Tuan destaca também outras razões para a mudança de atitude: "era mais fácil viajar, à medida que o século avançava. As montanhas que se tornaram acessíveis perderam muito de sua aparência proibida. A emoção declinou com a familiaridade." (TUAN, 1980, p. 84). Um outro momento significativo na avaliação das montanhas reside na sugestão turística e no poder de recuperação da saúde. Daí a geração de sanatórios, hotéis e facilidades turísticas. A Suíça sagrou-se o lugar do ar puro e da benignidade, ao contrário do horror e da aversão que antes provocava. Vários escritores da literatura mundial se internaram em casas de saúde na Suíça para se curarem da tuberculose. Enfim, a partir de meados do século XIX, definitivamente foi abandonada a concepção primeira que norteava o pensamento do homem em relação à montanha. Surgia, pois, uma nova percepção da paisagem.

\section{Identidade e memória do povo português}

A valorização da região de Trás-os-Montes na obra de Miguel Torga adquire, diante da trajetória tecida por Tuan, importância indiscutível, dado o caráter emblemático que detém no contexto da narrativa. A projeção nos personagens de sentimentos próprios do povo português certifica a identificação com a sua territorialidade, com a construção de uma nação capaz de superar-se de forma contínua. Por meio da simplicidade e da escrita interiorana, "o Portugal de Torga é antes de mais o das suas criaturas, descritas sem complacência mas com fundo sentimento de identidade de destino (...)" (Lourenço, 1995, p. 09). 
Esse dispositivo de enaltecimento da alma portuguesa a partir da valorização da terra está presente de modo explícito em "A Maria Lionça", mais exatamente quando da "viuvez" a que foi acometida. O narrador, ironicamente, se reporta à passagem antológica do Velho do Restelo de Os Lusíadas, depois retomada por Fernando Pessoa em Mensagem, em que é possível depreender a consciência telúrica dos que foram obrigados a aceitar o desbravamento dos mares em prol das descobertas de além-mar. Todavia, ao contrário de Camões e de Pessoa, Torga procura despertar no povo português não mais a sua condição de explorador de terras desconhecidas sob o lema do sacrifício. Não. O que conta agora é construir legitimamente no útero da terra a vida que deve nascer. De modo visceral, a identidade está no lugar, e não no espaço da inexperiência.

A Maria Lionça, essa, ficou. Como todas as mulheres da montanha, que no meio do gosto do amor enviúvam com os homens vivos do outro lado do mar, também ela teria de sofrer a mesma separação expiatória, a pagar os juros da passagem anos a fio, numa esperança continuamente renovada e desiludida... (Torga, 1996, pp. 18-19).

O mesmo acontece quando Pedro resolve partir de Galafura para Lisboa e depois se tornar marinheiro. O narrador de Torga qualifica o ato de "insensato" e mais: taxa o filho de Maria Lionça, fruto da terra e das dificuldades da montanha, de um "proscrito".

Teresa Rita Lopes declara natural essa tomada de atitude de Torga ao afirmar que: "É costume dizer que Torga aborrece o mar.(...) o mar é um seio de perdição que desgraça os que sucumbem ao seu apelo que, por sua vez, fazem a infelicidade dos que a eles estão ligados...” (Lopes apud Fernandes, 1992, p. 373). Acrescenta ainda que, para Torga, é "o apetite do Longe que leva o homem a trocar a Terra pelo Mar, a trair a raiz com o barco.” (Lopes apud Fernandes, 1992, p. 371). Na ótica de Torga, até a morte do indivíduo é recuperada pela terra que o faz ressuscitar. No mar, o que se dá é o mergulho no desconhecido e a ânsia pelo poder, tão ambicionada pelos portugueses nos séculos de ouro das grandes navegações. Semelhante concepção é sugerida por Yi-Fu Tuan agora em obra bem mais recente: Paisagens do medo (2005), ao tratar do capítulo intitulado "Exílio e reclusão". Em dada passagem, quando abre a discussão para o exílio ou reclusão dos doentes mentais, lembra do recurso de certos países europeus para se "desvencilharem" de seus loucos: enviava-os em barcos a lugares distantes. Assim:

no "barco dos loucos", as imagens de loucura e água estavam habilmente associadas: a água, um meio fluido expressando um estado que necessita de definição, é um símbolo adequado da loucura. Em contraste, a sanidade é a terra firme que as mentes instáveis esperam alcançar e aí se ancorar. (Tuan, 2005, p. 300)

O que se verifica em "A Maria Lionça” é a defesa incondicional da sanidade, representada pela personagem-título e, consequentemente, pela montanha, dada a indefinição das águas que leva à loucura. Num ímpeto de fuga e de frustração, tanto pai quanto filho buscam pelo mar o exílio, uma forma de esquecimento do desencanto vivido e da insatisfação com o mundo. A fidelidade à terra está na imagem da âncora, que "susta o movimento da vida quando este se torna tempestuoso" (Chevalier \& Gheerbrant, 1995, p. 50). Além da ideia de 
fidelidade, perpassa pela âncora o "símbolo de firmeza, de solidez, de tranqüilidade (...). Simboliza a parte estável do nosso ser, aquela que nos permite conservar uma calma lucidez diante da onda de sensações e sentimentos." (Chevalier \& Gheerbrant, 1995, p. 50). Maria Lionça sabe disso, daí a aceitação passiva e resignada do regresso do marido em estado de decrepitude e da viagem inesperada com o intuito de resgatar o filho já morto. Ambos devem "dormir o derradeiro sono" em terra firme que será a depositária de seus "ossos descarnados". Ela é a âncora da família e símbolo da identidade portuguesa, outrora imersa no movimento incessante do mar que seduz pela ambição e desejo de poder.

Se a topofilia pressupõe a afetividade humana, no caso aqui analisado, para os habitantes de Galafura, o mar é o reino por excelência do exercício do sentimento de topofobia, dada sua condição de infidelidade e de intranquilidade. Se a esses habitantes da montanha lhes fosse permitido, aniquilariam, deliberadamente, as águas - espaço da deserção do sentimento de paz e da construção do afeto.

\section{Considerações finais}

Ao longo da leitura de "A Maria Lionça", conto de abertura do livro Contos da montanha, de Miguel Torga, foi possível evidenciar a importância da paisagem vivida que preserva e transmite os valores e percepções dos grupos culturais ali envolvidos. Em Galafura, considerado o berço da personagem protagonista, a presença da montanha não conota simplesmente superioridade e altivez. Seu verdadeiro valor reside no poder de abrigar, de acolher com resignação e humildade os filhos da terra e aqueles que à Maria Lionça se uniram, como foi o caso de Lourenço Ruivo, o marido desertor.

A preservação da memória de Galafura não morre com o desaparecimento de Maria Lionça, que acontece no presente da narrativa. Afinal, sua semente foi plantada, não obstante as tentativas de fuga para o espaço desconhecido e sedutor, empreendidas pelo próprio marido e pelo filho a quem denominou Pedro e de quem supunha tudo, menos o exílio no mar. O destino, apesar dos atos de traição, a recompensou com o retorno inevitável de Lourenço e com o resgate do filho morto. No cemitério de Galafura, descansam em seu colo, na raiz do seu regaço protetor.

O estudo da paisagem, entendido como um conceito cultural do Ocidente, surgido com o Renascimento e já identificado por Tuan, implica assim um modo de ver o mundo onde entrariam em confronto o olhar do nativo e o do estrangeiro. O que se passa em "A Maria Lionça" reflete exatamente essa maneira de ver a paisagem: para a personagem-título, a montanha simboliza a sua vida e a sua alma. Seria impossível pensar em viver em outro lugar em que não pudesse sentir o húmus de sua terra. Para o estrangeiro, ao contrário, sem raízes fincadas em Galafura, não interessa o lugar, a estabilidade, antes o espaço a ser descortinado e com vistas a determinado objetivo. Foi o que se pôde constatar com Lourenço Ruivo que, mesmo sendo natural de Galafura, a abandona em prol da mutabilidade e, indiretamente, com Pedro que, desencantado com a imagem que havia construído do pai, desencanta-se também com a montanha e parte para o estrangeiro, para o que não pertence a Galafura. Esse confronto só é solucionado quando ambos recompõem as raízes com sua terra, ainda que na presença da morte. 
Maria Lionça concebe Galafura como sua pátria. "Pátria é a paisagem que temos experienciado", como acentua Leonardo Doob (1952, p. 16), citado e traduzido por Tuan. E a terra que se frutificou com o trabalho e as lutas dos antepassados e, graças a isso, se fortifica na sua grandeza. Ser terrestre, para Torga, é ter a imbricação com a terra.

Em reação ao apagamento da identidade portuguesa, Torga imprime no conto a força e a beleza do feminino e fecunda, na consciência dos portugueses, a necessidade de se pensar Portugal hoje em função de sua territorialidade, que se contrapõe à ambivalência e à transitoriedade do mar, horizonte do passado português. A abnegação, a afetividade e a compaixão se tornam valores a serem cultivados permanentemente no coração do indivíduo, traduzindo sua subjetividade e inserindo-o no mundo. Um transmontano sabe muito bem o que é isso. Para Torga, "onde estiver um transmontano está qualquer coisa de específico, de irredutível. (...), mesmo transplantado, ele ressuma a seiva de onde brotou. Corre-lhe nas veias a força que recebeu dos penhascos, hemoglobina que nunca se deteriora." (Torga, 1969, p. 60). Enfim, a experiência telúrica e cultural impressa em "A Maria Lionça”" emoldura-se em paisagem e em memória.

\section{REFERÊNCIAS BIBLIOGRÁFICAS}

BACHELARD, Gaston. A poética do espaço. Trad. de Antonio de Pádua Danesi. $2^{\mathrm{a}}$ ed. São Paulo: Martins Fontes, 2008.

CHEVALIER, Jean \& GHEERBRANT, Alain. Dicionário de símbolos. 9a ed. Rio de Janeiro: José Olympio, 1995.

CLAVAL, Paul. Geografia cultural. $2^{a}$ ed. Florianópolis: Editora da UFSC, 2001.

DIONÍSIO, Ângela Paiva, MACHADO, Anna Rachel, BEZERRA, Maria Auxiliadora (Orgs.). Gêneros textuais e ensino. $4^{\mathrm{a}}$ ed. Rio de Janeiro: Lucerna, 2005.

DOOB, Leonard W. Patriotism and Nationalism: their psychological foundations. New haven: Yale University Press, 1952.

FERNANDES, Francisco Cota. "Sou um homem de granito" - Miguel Torga e seu compromisso. Lisboa: Edições Salamandra, 1992.

LOURENÇO, Eduardo. O Portugal de Torga. Revista Colóquio de Letras $\mathrm{n}^{\circ}$ 134/136, janeiro/junho. Lisboa: Fundação Calouste Gulbenkian, 1995.

SILVA, Vera Lúcia L. Paredes. Variações tipológicas no gênero textual carta. In: $\mathrm{KOCH}$, Ingedore Vilaça e BARROS, K.S.M. (Orgs). Tópicos em linguística de texto e análise da conversação. Natal: EDUFRN, 1997.

TORGA, Miguel. Trás-os-montes no Brasil. Traço de união. $2^{\mathrm{a}}$ ed. revista. Coimbra, Ed. do Autor, 1969.

. Contos da montanha. Rio de Janeiro: Nova Fronteira, 1996.

TUAN, Yi Fu. Topofilia: um estudo da percepção, atitudes e valores do meio ambiente. Trad. de Lívia de Oliveira. São Paulo: DIFEL, 1980.

. Espaço e lugar: a perspectiva da experiência. Trad. de Lívia de Oliveira. São Paulo: DIFEL, 1983. 
TUAN, Yi Fu. Paisagens do medo. Trad. de Lívia de Oliveira. São Paulo: Editora UNESP, 2005.

WEBER, Lúcia Maria Domingues \& THIMÓTEO, Maria Natália Ferreira Gomes. Maria Lionça de Miguel Torga: mulher, mãe e terra. UNICENTRO - Revista Eletrônica Lato Sensu. Edição 5, 2008. 